\title{
Exponential Technologies + Reverse Innovation = Solution for Future Healthcare Issues? What Does It Mean for University Education and Entrepreneurial Opportunities?
}

\author{
Michael Friebe \\ Institute of Medical Engineering, Otto-von-Guericke-University, Magdeburg, Germany \\ Email: michael.friebe@ovgu.de
}

How to cite this paper: Friebe, M. (2017) Exponential Technologies + Reverse Innovation $=$ Solution for Future Healthcare Issues? What Does It Mean for University Education and Entrepreneurial Opportunities? Open Journal of Business and Management, 5, 458-469.

https://doi.org/10.4236/ojbm.2017.53039

Received: May 11, 2017

Accepted: July 7, 2017

Published: July 10, 2017

Copyright $\odot 2017$ by author and Scientific Research Publishing Inc. This work is licensed under the Creative Commons Attribution International License (CC BY 4.0).

http://creativecommons.org/licenses/by/4.0/

\begin{abstract}
Exponential technologies are generally described as something that will-in a given time period-double data generation/evaluation and/or half the associated cost with it. The terminology is actually only proven for the Information and communication technology (ICT) segment at the moment, where according to Moore's law the complexity of processors and the cost per transistor follow that path for many decades now. An example from Medical technology is the cost of genome sequencing that has dropped from millions to thousands and now to under USD 100 within a little more than a decade. In many other areas there are potential and hope that certain technologies (see Figure 1) could lead to significant clinical knowledge gains and procedure improvements combined with cost reductions. But is this just a hype or something that in combination with other emerging technologies could really provide solutions for the problems that we will face in present and future healthcare delivery? Specifically the increasing life expectancy and the ageing societies in combination with less and less available healthcare staff, ever increasing cost associated with healthcare delivery/products and services, or the inequalities between rural and urban areas particularly in developing nations that need to be addressed urgently. This paper will present the potential impact of some exponential technologies-in selected areas-on the future challenges of healthcare delivery with a particular focus on reverse innovation, where new technologies and delivery approaches will be first implemented in developing nations before being accepted and adopted by the developed world. It will also point out some changes that need to be implemented by universities for the education of future medical technology developers and the effect that could have on entrepreneurial opportunities.
\end{abstract}




\section{Keywords}

Exponential Technologies, Reverse Innovation, Healthcare, Entrepreneurship, Healthcare Demographics, Prevention

\section{Introduction}

The global healthcare market is currently greater than US\$ 3 trillion and growing. It is expected, that in the United States one quarter of the total gross domestic products will be spend on healthcare within the next two decades.

In the developed world healthcare is-with very few exceptions-dealing mainly with sick people however, within a complex, expensive, and overly bureaucratic environment. There is very few focuses and money spent on preventing people from getting sick.

Avoiding medical problems potentially has a huge negative financial impact for healthcare companies, clinical service providers, and everyone involved in healthcare delivery [1].

On the other hand, staying healthy comes with a huge positive impact for the personal quality of live and on the total cost of healthcare for the society.

Many procedures currently performed for example are not clinically necessary and done just to avoid malpractice and liability issues [2].

At the same time there is a growing concern that the healthcare industry's focus is, at the moment, mainly on developing advanced technologies that only help the relatively small population of the developed world, rather than to invest money into providing products and services that would simplifythe complexity ofhealthcare.

Simplification could potentially lead to truly innovative technologies that benefit most patients on this planet and provide preventive and personalised solutions.

What are the requirements to open healthcare for these technologies so that they can have a huge and positive impact (Figure 1)?

\section{Digital Transformation}

Systems that combine advanced hardware with Artificial Intelligence (AI) willin the next two decades-be able to provide diagnostic information that should be equally available to the poorest and wealthiest on Earth.

The patients genomic sequence and machine learning will allow us to understand the root cause of many non-communicable diseases like cancer, cardiovascular and neurodegenerative problems, and also provide information and advise on what to do about it.

Robotic systems are currently tele-manipulated devices operated directly or via remote connections through surgeons. That will expand and also make advanced surgeries possible at remote locations, but eventually AI will help to create robotic surgeons that will be able to carry out excellentsurgical interven- 


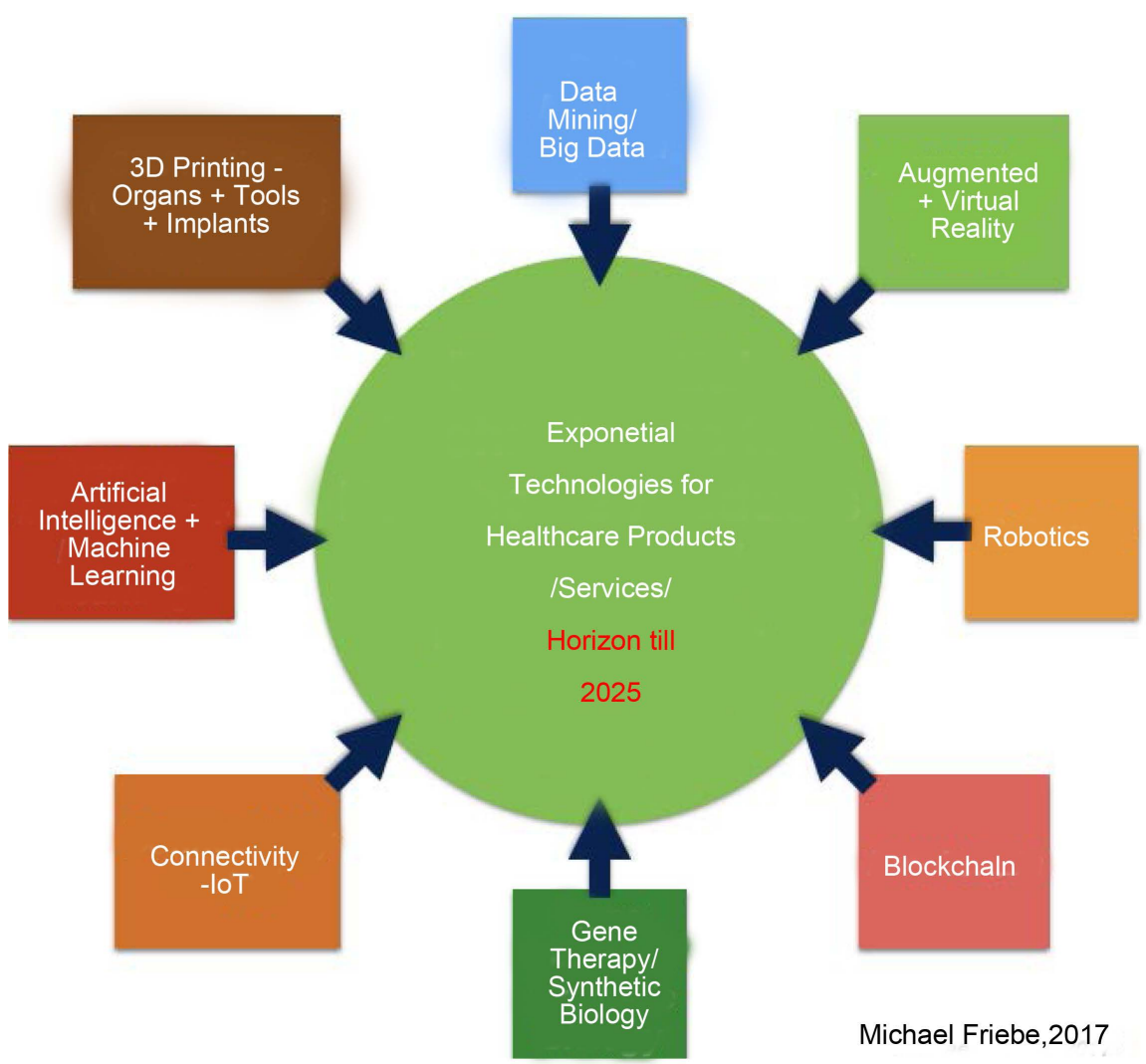

Figure 1. Exponential Technologies will potentially introduce dramatic changes in the coming decades, moving to a value based and patient centric healthcare system that will have a proactive focus on preventing people from becoming sick rather then to reactively treat the ones that become sick.

tions for very little cost and on a 24 hour basis.

$3 \mathrm{D}$ printing is already able to provide $3 \mathrm{D}$ cell models of organ tissue. It is therefore quite likely that we will eventually be able to regrow a heart, liver, lung or kidney when we need it instead of waiting for a donor to die. Even more realistic is a personalised 3D print of a bone implant produced either preoperatively or during the surgery with a fast printer that is directly fed with the data from the surgical table.

One of the pre-requirements for all these technologies is digitisation. Processes and services that cannot be digitised will-for the time being-be impossible to grow or improve exponentially.

The associated digital data content is key to analysis, evaluation, learning, drawing conclusions, and subsequently providing the required information for personalised and individualised therapy decisions and outcome improvements. It will also be essential for a transformation from a reactive to a proactive healthcare delivery.

We have already started that process with the large number of healthcare apps that are available and by recording all kinds of personal data with the support of wearable sensors. While most of these sensors and apps are for personal use only at the moment and are not used in the official clinical diagnosis yet, that will 
change for sure.

Healthcare participants (so everyone) will use sensor systems for blood pressure-, glucose-, behaviour-monitoring and many other applications (Figure 2).

They will use their Internet of Things (IoT) devices to connect directly or via smartphone to cloud servers that make the data available for researchers, regulatory offices and also healthcare providers (doctors, hospitals, ...).

These home-based and personally used technologies and the data generated by them will eventually lead to providing fast, and personalised healthcare status information directly to the patient.

The patient does not have to go in person to see a doctor for a majority of causes, but instead gets detailed feedback and even a prescription digitally. In case of urgent or immediate clinical intervention a clinical expert would be contacted and an appointment made or an ambulance dispatched.

Healthcare prevention is currently mainly limited to exercise and nutrition and only complemented by a voluntary clinical feedback every other years.

In the near future home-based or personally worn sensors and other technologies would give much more detailed, fast, and regular feedback on the current healthcare status. Improvements or situation worsening could be monitored and combined with follow-up clinical treatments were needed and indicated (Figure 3).

So instead of an early and reactive transition from home to the healthcare system, as is typical for today, a future healthcare system will stimulate pro-

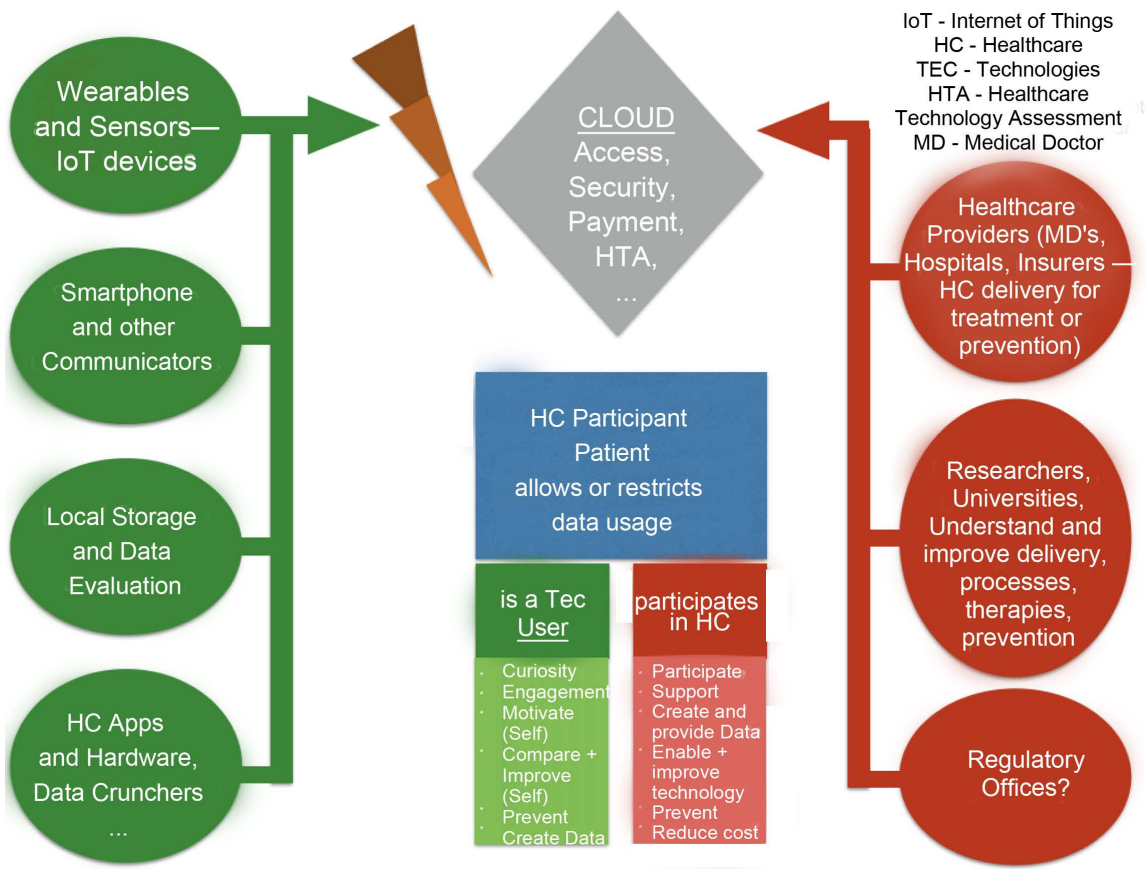

Figure 2. In the very near future wearable sensors, healthcare apps and the smartphone will provide data for researchers, healthcare providers, and regulatory offices that are actually used for making personalised decisions and that will provide some of the needed datasets to potentially solve the non-communicable disease problems proactively. 
HOME - 2017 - LITTLE FOCUS
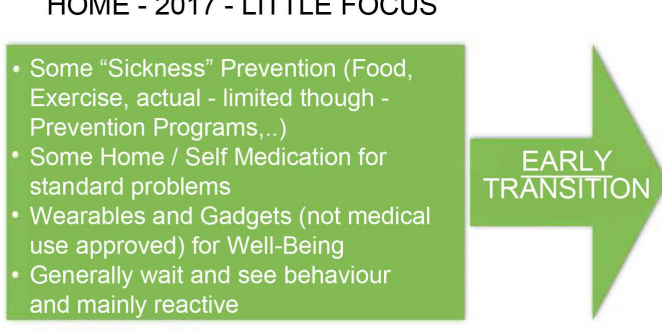

HOME-2037- HIGH FOCUS
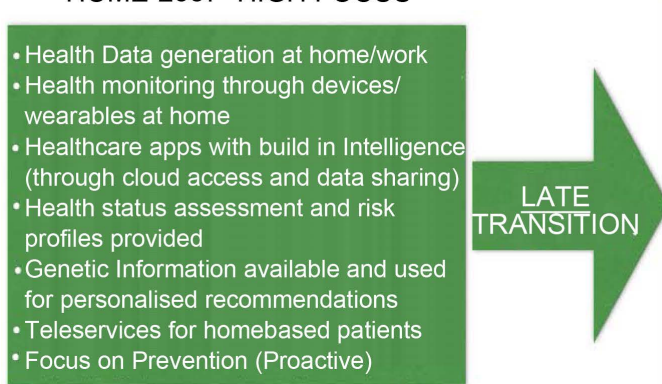

HEALTHCARE - 2017 - MOSTLY

Ambulatory Care (outpatient) through

General Practitioner followed by

Pharmacist,... and on case by case by

Medical Specialist. .

and depending on outcome and

diagnosis by Stationary Care

(Inpatient) in Hospital

or direct Stationary Care in case

of Emergency or Accident

Payment if patient is sick and treated

HEALTHCARE - 2037 ONLY WHEN REALLY NEEDED

More centralised + specialised care

- Fast + initial contact through teleservice

- Advanced diagnostic systems available

including molecular + anatomical details

- Data transfer from homebased Software

+ Hardware including data interpretation

Artificial Intelligence + Big Data

evaluation for individual report and

recommendation

- Artificial + personalised Implants and

Tissue Replacements

- Payment if patient stays healthy and

goes back healthy after treatment

Figure 3. The current healthcare system is based on being reactive to treat a patient when he/she becomes sick. The clinical providers receive payment for that. In the future the transition from a home-based prevention and information based system is relatively late to an actual clinical treatment. Healthcare providers should be paid if the patient leaves healthy and subsequently stays healthy.

active prevention, provide personalised healthcare status and recommendation, and transfer the patient relatively late to become a real patient.

Many challenges and issues remain, like regulatory permissions, reimbursement and payment, data privacy and of course general adoption of such a setup. It can already be safely forecasted though, that some home-based diagnostic platforms will soon arrive and with that start to establish medical care at home [3].

Interpretation of diagnostic images, an essential and very important part of analysing a patients health and to subsequently provide information for a treatment/surgery, is believed to be one of the first disciplines to be dramatically effected by AI and Machine Learning.

A pre-requirement is however that the images provided by the radiology systems are standardised and that the obtained results are comparable to each other. These could then be shared and combined with additional information to create a multi-dimensional data set. This subsequent data set can be analysed by computers most likely better than by human radiologists, who will be "freed from many repetitive and mind-numbingly tedious tasks", but will shift the work to added value in image interpretation. So, while it is likely that the standard image interpretation will disappear for the radiologist (and for that matter clinicians in other segments that my be affected by the new technologies) there will be other responsibilities and opportunities for the human radiologists 
[4] [5].

New technologies will not only change the diagnostics, but will also have a huge effect on the treatment of for example cancers. We will there see new imaging systems that are combined with robotics and radiation therapy systems. These systems will be able to distinguish between the cancerous and healthy cells and only selectively kill, which will resultin a very personalised treatment with minimum side-effects. However, for that a fast on-site digital pathology is also needed [6].

Even surgery, while being a manual discipline, will be digitised. Modern surgery has to be concerned about outcome of the surgery, associated cost of surgery and rehab measures, as well as about the inflicted surgical trauma. Ehealth and IoT connection of all surgery devices and associated systems (lighting, diagnostic imaging, monitoring equipment, surgical table, ...) will be a key for improving efficiency and accountability. The captured data and subsequent analysis of the patient specific data (genetic, pre-diagnostic, histology, ...) with the surgical procedure and outcome will provide optimised surgical models with the help of machine learning and AI approaches. Complicated cases could also be supported by experts through advanced telesurgery procedures from anywhere in the world [7].

And many other applications from prevention to treatment, subsequent rehabilitation, and elder care or home-care will be influenced by the digitisation promising a faster, more efficient, and cheaper healthcare delivery in the coming decades [8].

But will these technologies also be able to address unequal delivery of healthcare in developing nations? Or will the developing nations be providing solutions that are also applicable for use in developed nations?

\section{Reverse Healthcare Innovation}

One of the major problems for the implementation and acceptance of new technologies in the healthcare systems of the developed world is the current setup and associated adoption issues. Also, the regulatory environment in Europe, Northern America and Japan is already very complicated and slow ... and, it will probably get even more complicated and slower in the near future.

While it is obvious that health care providers will receive less revenue in the future there is no real interest to rethink the current healthcare delivery and to start thinking about more cost-efficient solutions. Some of these solutions have been developed by the developed world for developing nations and a few others are directly originating there that address vital local problems.

Reverse Innovation - the introduction of these solutions originally meant for developing nations by developed nations-may be one way that healthcare systems can decrease per-capita costs and increase quality at the same time [9].

High-priced and complicated medical equipment is normally produced by developed nations for developed nations and is typically installed and used for 5 - 15 years. After that it is exchanged by a Next Generation Product that more or 
less does the same task, but better, faster, with more features-something called sustaining innovation. The old equipment is then often sold as used or refurbished to emerging or developing nations, but maystill be to complicated to install/operate or may only be useful/accessible to a very small part of the population there.

An alternative is to build a lower specified system that more closely fits the requirements of the healthcare system and clinical needs in these nations.

What we will see more often in the future is that these nations actually will build dedicated systems for the needs of their population that are typically quite simple, very efficient, and can be manufactured for a fraction of the cost of the advanced technologies that are produced by the developed nations.

Yes, these products most likely do not provide the same features, and may be slower, or lower specified ... but they may be applicable for a majority of the cases even in the developed world and/or when used in rural areas. These point of care and local technologies could therefore have a valuable use in our healthcare systems as well. This process of adopting low-cost, efficient,and easier solutions from developing nations is called Reverse Innovation and highlighted in Figure 4.

It has been proven that developing nations can come up with and subsequently develop and produce extremely efficient products addressing local problems that could substitute expensive products in the developed world and therefore could easily be transferred [10].

Current Approach for Medical Technology Transfer

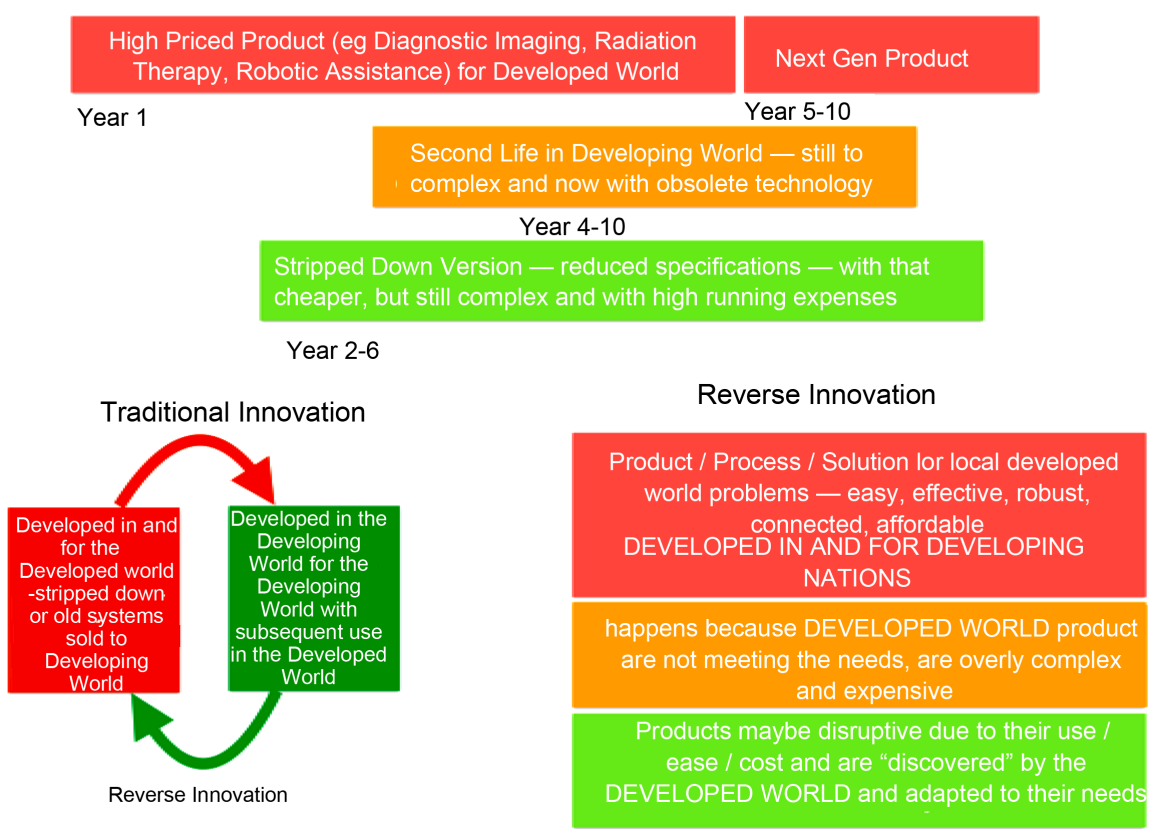

Figure 4. The traditional and current innovation process for medical technology is an either stripped down or used product that comes from a developed nation to a developing nation. Reverse Innovation-developing a product in a developing nation that is subsequently transferred for use to a developed nation-could be a way to reduce inequalities and also help to reduce the healthcare cost in the developed world. 
Companies located in the developed world have a hard time accepting that however, as it would stipulate a complete rethinking and reorganisation process of their operation. Only very few companies have therefore invested in reverse innovation. But the ones that did were rather successful [11].

A solution could be a combined learning process between organisations/ companies in developing and developed nations specifically looking at creating cost-effective, easy, small and with that valuable products and processes that are helpful for a global health systems [12].

And there is plenty of data supporting such joint activities and the value of a development focus on creating less expensive devices. While only $13 \%$ of the medical technology manufacturers are located in lower income countries almost two third of the incremental health care spending is used for affordable technologies. The products that come from these low income nations very often are quite disruptive and creative, with a technology basis that is significantly simpler that competing technologies from developed nations.

A recipe for joint developments between Low Income (LIN) and High Income nations (HIN) could be:

1) What medical needs are common to LIN and HIN.

2) Start the innovation process in the LIN.

3) Initiate the Reverse Innovation process and introduce to HIN with proven concept in LIN.

4) Implement and establish the technology in HIN.

But this process and the focus on disruptive value based clinical innovation can also be initiated and managed by entrepreneurs through dedicated start-up companies in LIN or HIN [13] [14].

\section{Importance of Entrepreneurship for the HC transition}

Without entrepreneurs that challenge the current setup and that come-up with alternative and new systems, methods and processes a healthcare change as outlined will not happen soon.

The large medical device companies and healthcare providers do not have a large enough incentive to start a rethinking process immediately and to a full extend. Part of this slow and little radical innovation process are regulatory issues and high cost of entry.

But, we are now on the way to a late transition from home-care to the healthcare providers and from a reactive healthcare delivery process to a more prevention oriented and personalised pro-active one.

There will for sure be entrepreneurs that will tackle and address the opportunities that come with such a transition and that will nevertheless put the patient in the midst of their thinking, while maintaining the regulatory rules that come with new healthcare products and services [15].

These entrepreneurs (and the more progressive established medical technology suppliers and healthcare providers) will also learn that valuable products and services can be developed and introduced adapted to the local needs with 
key value propositions like inexpensive and easy to use.

These local needs include special diagnostic and/or therapy systems to address different disease patterns, dedicated and simple technical support and training, availability of inexpensive spare parts, affordability of system and related medical service for all not just a minority, and fulfilment of all applicable regulatory issues. These systems could also open opportunities for local manufacturing, servicing, and support companies with that creating employment and tax income [16].

Entrepreneurs in that segment will understand that success is predominantly based on the knowledge of the local markets and customer needs. These needs are locally different and may require completely different product features when HIN and LIN are compared to each other (Figure 5).

Finding these differences and designing the product/service that fits to the local market, requires dedicated need finding in a combination between technical and clinical innovators. And, it also requires a different skill set that is commonly not provided as part of a university based training.

To address the mentioned healthcare innovation, reverse innovation and entrepreneurial opportunities, a special skill set and dedicated knowledge is required that can only be taught in a university within a new degree program.

\section{University Based HC Innovation Education-Changes Needed}

University education will make you a good doctor or an excellent engineer or possibly a great economist-depending on your choice of subject. But it does not prepare the student for being a future leader in healthcare innovation. The skill set needed for that-in an interdisciplinary triangle environment between technical possibilities, medical needs and economic realities-is quite different from the either technical/clinical/or economic foundation that is provided as part of a university training (see Figure 6).

You need to be creative and visionary and also be trained in personal skills, like leadership, social responsibility and in an empathic understanding of

MedTec Development Success Factors / Tips

\section{MARKET AND CUSTOMER KNOWLEDGE: Patient Need is known, User Need is known, Unmet Clinical Need is discovered and verified, Market Dynamics understood}

PRODUCT FEATURES: Differentiation, Ease of Use /

Simple, Affordable and Efficient, Connectivity / loT

OTHERS: Regulatory Compliance,

Serviceability, Commercial Use

Michael Friebe. 2017

Figure 5. Successful local healthcare products and services are predominantly related to how well the market and customer needs are known. This then determines the local features and regulatory compliance issues. 
HC 21st CENTURY - EDUCATION SKILLS NEEDED
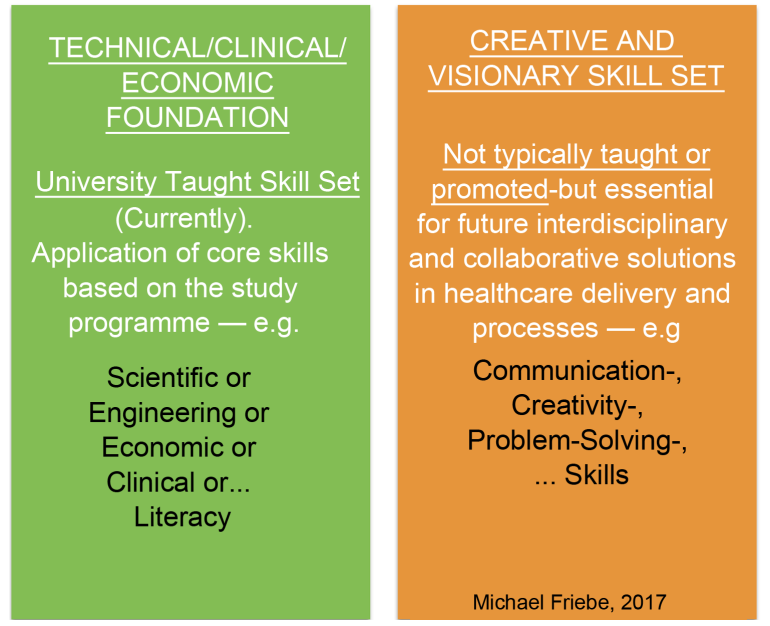

PERSONAL SKILLS

Big lack of personal and

character skills — very

rarely addressed, and

mentored in a University

Setup, needed for

Entrepreneurial Activity,

Change, Management

Empathic and Social

Changes, Innovations

e.g. Empathy and

Social

Responsibility,

Leadership, Self-

Initiative,....

Figure 6. 21 st century healthcare innovation requires a special set of skills that are typically not part of a university based education. While the technical/clinical/economical foundation is standard for a dedicated university education the creative, visionary, and personal skills are generally not taught especially not in the context of healthcare innovation.

problems and concerns of any participant in the healthcare system including (but not limited to) patients, doctors, and other clinical staff.

Entrepreneurial basics with a focus on healthcare need to be addressed and taught. Future entrepreneurs that can collaborate with the medical device or healthcare provider industry, researchers, clinical staff and public organisations, will have a distinct advantage and be able to more easily identify real innovations solving medical needs [18].

And that not limited to just incremental innovations. These are of of course needed, but they will not solve the problems with healthcare cost constraints, availability of treatment options for everyone and everywhere, personalised approach to cancer treatment,..., and many others.

Disruptive ideas and concepts are needed that could potentially solve a lot of these problems and at the same time provide large business opportunities, which are however hard to implement in modern healthcare systems [17].

A new study program (Bachelor or Master or Post-Graduate) incorporating knowledge of healthcare system and provision, innovation challenges and strategies, basic knowledge of clinical problems and future oriented technical possibilities, interdisciplinary and international team work, combined with management and entrepreneurial skills should be initiated.

\section{Discussion \& Conclusions}

Exponential technologies could lead to a dramatic change in the way that healthcare is delivered. Currently, almost all of the national healthcare systems treat sick patients rather than to prevent people from becoming patients. The future will be a pro-active predominantly data based healthcare that will collect, process, and analyse information providing a personalised report that would also 
allow preventive measures [1].

Digitisation is a key requirement for these developments. With that real disruptive medical technologies could be developed, which would change diagnosis, treatment, billing, financing, and many other aspects of healthcare delivery [2] [19].

These disruptions may come with convinience to use, less complex, and much more affordable solutions; some of them originating from low income nations that are subsequently adapted by the developed world as they have proven to provide adequate or even superior solutions for a fraction of cost.

Entrepreneurs will play a vital role in the future change of healthcare, as they will develop and introduce solutions that are based on addressing local clinical needs. Entrepreneurship education is still not seen as a core responsibility of universities however.

But these changes in technology, leading to completely new business models, will require innovation leaders that have a skill set that fits the 21st century healthcare challenges, that are not taught in conventional university based study programs.

For that we would need a new type of lecture-Bachelor or Master programthat combines basics of economical, technical and clinical knowledge with management skills, innovation techniques, entrepreneurship, and social skills for working as a leader of interdisciplinary and international development teams. Healthcare is a global problem and therefore these future programs should be very international with respect to the student population and the teaching faculty.

\section{Aknowledgements}

The and research was supported by the German ministry of education and research-BMBF- under grant 03IPT7100X. This article was written as introductory statement to the 5th BME-IDEA Europe (Biomedical Engineering-Innovation, Design, Entrepreneurship Alliance) meeting at the Otto-von-GuerickeUniversity in Magdeburg, Germany, June 2017.

\section{References}

[1] Christensen, C., Bohmer, R. and Kenagy, J. (2000) Will Disruptive Innovations Cure Health Care? Sept.-Oct. 2000 Issue Harvard Business Review. https://hbr.org/2000/09/will-disruptive-innovations-cure-health-care

[2] Diamandis, P. (2016) Disrupting Todays Healthcare System. http://www.diamandis.com/blog/disrupting-todays-healthcare-system

[3] Kraft, D. (2016) The Future of Healthcare Is Arriving-8 Exciting Areas to Watch. https://singularityhub.com/2016/08/22/exponential-medicine-2016-the-future-of-h ealth-care-is-coming-faster-than-you-think/

[4] Reiser, M. (2017) Possibilities and Challenges of Radiology-Presentation of Prof. Maximilian Reiser during the 2017 MR Conference in Garmisch, Germany.

[5] Hricak, H. (2016) Beyond Imaging-Radiology of Tomorrow. Keynote Lecture RSNA 2016. http://www.rsna.org/News.aspx?id=20286 
[6] Mertz, L. (2017) Tech Fights Toughest Tumors: New Robotics Capabilities, Radiation Technologies, and Methods for Spotting Tumor Cells Lead the Way Forward. IEEE Pulse, 8, 8-13. https://doi.org/10.1109/MPUL.2016.2627458

[7] Feussner, H., Kranzfelder, M., Wilhelm, D. and Schneider, A. (2017) Surgery 4.0. In: Thuemmler, C. and Bai, C., Eds., Health 4.0: How Virtualization and Big Dataare Revolutionizing Healthcare, Springer International Publishing. https://doi.org/10.1007/978-3-319-47617-9_5

[8] Saxena, A. (2015) 5 Remarkable Facts about the Future of Health Care. https://www.entrepreneur.com/article/243297

[9] Bottles, K. (2012) Reverse Innovation and American Health Careina Time of Cost Crisis. PEJ July/August 2012:S18:20.

http://ldihealtheconomist.com/media/reverse_innovation_and_american_health_ca re_in_a_time_of_cost_crisis.pdf

[10] Immelt, J., Govindarajan, V. and Trimble, C. (2009) How GE Is Disrupting Itself. Harvard Business Review, 87, 56-65.

[11] Govindarajan, V. (2012) A Reverse-Innovation Playbook. Harvard Business Review 04/2012. https://hbr.org/2012/04/a-reverse-innovation-playbook https://doi.org/10.1108/sd.2012.05628iaa.008

[12] Syed, S.B., et al. (2012) Developed-Developing Country Partnerships: Benefits to Developed Countries? Globalization and Health, 8, 17

[13] DePasse, J. and Lee, P. (2013) A Model for "Reverse Innovation" in Health Care. Global Health, 9, 40. https://doi.org/10.1186/1744-8603-9-40

[14] De Passe, J.W., Caldwell, A., Santorino, D., et al. (2016) Affordable Medical Technologies: Bringing Value-Based Design into Global Health. BMJ Innovations, 2, 4-7.

[15] Hendricks, D. (2016) Why Entrepreneurs Are the Future of Healthcare. http://www.inc.com/drew-hendricks/why-entrepreneurs-are-the-future-of-healthca re.html

[16] Glifford, G. (2016) The Use of Sustainable and Scalable Health Care Technologies in Developing Countries. Innovation and Entrepreneurship in Health, 3, 35-46.

[17] Friebe, M. (2017) Healthcare Translation and Entrepreneurial Training in and for Egypt-Case Study and Potential Impact Analysis. Open Journal of Business and Management, 5, 51-62. https://doi.org/10.4236/ojbm.2017.51005

[18] Montgomery, M. (2016) The Future of Health Care Is in Data Analytics. https://www.forbes.com/sites/mikemontgomery/2016/10/26/the-future-of-health-ca re-is-in-data-analytics/\#13d4ee4a3ee2

[19] Mesko, B. (2017) The Medical Futurist. http://medicalfuturist.com 
Submit or recommend next manuscript to SCIRP and we will provide best service for you:

Accepting pre-submission inquiries through Email, Facebook, LinkedIn, Twitter, etc. A wide selection of journals (inclusive of 9 subjects, more than 200 journals)

Providing 24-hour high-quality service

User-friendly online submission system

Fair and swift peer-review system

Efficient typesetting and proofreading procedure

Display of the result of downloads and visits, as well as the number of cited articles Maximum dissemination of your research work

Submit your manuscript at: http://papersubmission.scirp.org/

Or contact ojbm@scirp.org 